\title{
Entitlement to Health Insurance in the Republic of Albania and the Europian Code of Social Defence
}

\author{
Fjoralba Memia, PhD Candidate \\ The Institute of Health Care Insurance \\ Phone: +3551672224325, Email: fmemia@hotmail.com
}

\section{Doi:10.5901/mjss.2013.v4n10p505}

\section{Abstract}

The entitlement to the health insurance is one of human rights and freedoms defined in the Constitution. It is part of social objectives of the State. The study aims to extend not only in the internal legislation but also to compare this with the most relevant and most important document of the field that is the European Code of Social Defense, confirming compliance with the lines and the main principles of this document. Paper also makes a quick analysis of some typical systems of health insurance in Europe. The purpose of this analysis is that by exploiting the spirit of the European Code of Social Security and analyzed systems experience, to offer appropriate solutions to concrete problems of various administrative and procedural law that are found during the development of the scheme in Albania.Also, the paper aims not only to provide a theoretical treatment of problems in this area, but also to give concrete practical suggestions, because the improvement of legislation in this area should be done in the context of a policy of harmonization with European standards and parameters.

Keywords:health insurance, social security, insuree, contributor,mandatory health insurance scheme

\section{Indotruction}

The right to health is affirmed at the international level with the Universal Declaration of Human Rights, Article 25, in 1948. Inter alia states that "Everyone has the right to a standard of life adequate for it's health and the well-being of his family.

Entering the constitution of the World Health Organization also confirms that it is a fundamental right of every human being to enjoy the highest attainable standards of health. Integral part of the right to health is also the right of the basic conditions of health and health care.

Albanian model of health insurance has realized this right preferring to keep in harmony legislation and institutions responsible for the organization and implementation of the right to health insurance.

Within the Albanian Constitution, the right to health insurance of citizens has taken place in the group of economic and social rights. It is also understood that the existence of this right is based not only in the human nature but is associated with the obligation and the interaction of the state to create special conditions so that this right can be accomplished. Considering the importance of health care, and in fulfillment of the obligations and of the constitutional objective, the state assumes facilitation and creation of conditions for the implementation of this right.

In respect of the Constitution, Law. 7870 dated 13.10.1994 "On health insurance in the Republic of Albania" amended, has created a national non-profit health insurance system, which guarantees the right to health insurance.

Our study aims to present the right for health insurance in Albania, in the context of the principles of the European Code of Social Protection also focusing is generally in health insurance systems in Slovenia.

\section{Overview of Compulsory Health Care Insurance Scheme}

\subsection{The principle of compulsory health care insurance scheme}

The right to health care is a constitutional right. The Constitution of the Republic of Albania in its Article 55 specifies that "All the citizens equally enjoy the right to health care provided from the state. Everyone has the right to health insurance in accordance with the procedure established by law." (Constitution of the Republic of Albanian, article 55)

The right to health insurance of citizens is included in the group of economic and social rights in the Constitution. This right is a positive one just like most of the rights that are part of this group. This conclusion is arrived based on the 
reference made by constitutional provisions when it conditions the application of this right to a special law which shall establish rules and its application procedure.

It is also understood that the existence of this right is based not only on human nature but it is associated with the obligation and the interaction of the state to create special conditions so that this right can be realized. The law no. 7870, dated 13/10/1994 "On Health Insurance in the Republic of Albania", as amended, fulfill the constitutional obligation of determining the procedure for realizing the right of watch individual to health insurance.

The law stipulates that health insurance in the Republic of Albania is compulsory. Compulsory health insurances scheme is universal because it covers all Albanian citizens residing permanently in Albania, as well as foreigners employed and insured in Albania. Theoretically, all population groups are covered by health insurance. However, the law provides for the opportunity to include in this protection any special individual whose insurance is not provided for by this law. This approach consists a further development in theconstitutional law for health insurance. Voluntary insured people are included in the scheme and have the right to benefit in the same way with all the contributory categories of the scheme. All persons participating in the scheme are considered as insured. Participation in the scheme is based on the payment of contributions. Contributions are paid from the income of economically active persons and from the state budget, which pays for economically inactive persons. Here we have to do withanother important principle of compulsory health insurance schemes-the principle of solidarity.

Pursuant to the law, the compulsory health care insurance scheme remains open for the non-active category as well. The Council of Ministers has the right to specify other groups of citizens in need, for which the state should contribute.

When certain individuals do not find themselves included in any category of the compulsory scheme, the law provides for the possibility of voluntary insurance implementation. These people, who may be housewives, emigrants, or students studying abroad may voluntarily join the scheme by paying contributions based on the minimum wage when they are in Albania. Once paying contributions, they benefit health insurance just like all other insured.

\subsubsection{Financial Resourcesand Contributionssizes}

Financial resources of the health insurance scheme are compulsory health insurance, comprising of contributions of economically active persons according to the categories specified in Article 8 of the law no. 7870, dated 13/10/1994 "On Health Insurance in the Republic of Albania"(Law no. 7870, 1994 ).This includes contributions from voluntary insurance, which means contributions from people who do not find themselves in the categories insured on mandatory basis, or in the categories for which the state pays.

- financing from the state budget, which means contributions for economically inactive persons, such as children, students, pensioners, persons with disabilities (mental and physical), the unemployed, people who receive social aid, mothers on maternity leave, but also other groups of beneficiaries, which can be determined by the government, depending on its social and health policies.

- donations

- $\quad$ other income, as bank interests, indemnifications, reimbursed prescription fees, specified categories (DCM no. 7870, dated 13/02/2003),etc

Employed persons (including foreigners) pay a fixed contribution of $3.4 \%$ of gross salary, in the minimum and maximum limits that are determined by the Council of Ministers. The paymentof this contribution is divided equally between the employer and the employees (1.7\%), for the self-employed and unpaid family workers exerting their activity in the city the amount of the contribution is $7 \%$ and for the self-employed and unpaid family workers exerting their activity in the village, the contribution is $5 \%$ for lowland areas and $3 \%$ for mountain and hilly areas(Law no. 7870 , dated 13/10/1994).

At first glance, this approach seems not to be in line with the principle of equality. Currently, the principle of equality is considered fulfilled when it comes to benefits, since the benefits from this scheme are equally provided to all insured persons who have the same health needs, regardless of the contribution that each of themhas deposited. It is clear that we don't imply hereequality concerning the specific amount of contributions, which any insurer shall be liable to pay. The idea was to find and establish a mechanism that would be applied equally for all insured, regardless of the specific values of contributions. One of such ways shall be for example, the unification of the contribution amount for all insured whether they are economically active or non-active. In this way, the insured will be treated equally in principle although specific fees will change depending on each individual salary. In this case, an upper ceiling has to be established on the maximum amount allowed to be considered for the calculation of contributions effect, a ceiling, which 
is currently 5 times the minimum wage.

\subsubsection{Identification of insured persons}

The document which indicates that the person is insured and that can benefit from all the services of the scheme is the health booklet(DCM. 86, dated 13/02/2003). Health booklet is delivered to the insured either by the Health Insurance Regional Directorates or the family doctor. In order to obtain health booklet persons must prove that they have paid contributions or belong to inactive groups covered by the State. For this reason, the persons must present one of these documents:

Social and health insurance contributions booklet (employees, self-employed, employers), retirement pension booklet for the pensioners, birth certificate for children, an authentication from the school for pupils and students, an authentication from the job office for unemployed job seekers, etc.. All of the above mentioned documents are arranged with DCM. 86, dated 13/02/2003 "For the health booklet". According to this decision, HII determines the form and content of this identification and personal document. The latter determines the manner of issuance, their fulfillment and use. In this way, health booklet is a document through which the status of individuals concerning insurance is identified under the provisions of DCM. 87, dated 13/02/2003 "On the identification and obligations of persons receiving health services in the Republic of Albania". This decision specifies identification of people that receive the service and ways of their identification through health care booklets. According to this decision, persons who are eligible to receive primary, secondary, tertiary and pharmaceutical health services, should be supplied with health booklets and take advantage of basic health insurance law. All those people, who do not present documentation proving that they are the beneficiaries of health care services, have to make full payment to receive the health service that is for the medical treatment and drugs .

\subsubsection{Coverage of costs in primary health care}

Since 1995, after the insurance scheme was enforced and up to 2006, the scheme covered only the costs of the services provided by family doctor (GP) in primary health care(World Bank, Problems, Issues, and Alternative Approaches). These costs included physician payment and coverage of simple check up costs. Each ensured individual is registered at the family doctor and they have the right to change the family doctor to his/her discretion, but not more than once a year. This section of the scheme doesn't provides for co-financing, which means that the insured person does not pay anything for visits and other services in outpatient primary service. Uninsured person pays according to the rate approved by the Council of Ministers. The health service benefited once the insured person submits the health booklet.

At the end of the visit, the doctor prescribes prescription with full or partial refund to the insured and unreimbursed prescription for the uninsured. The relations of the physicians with insurance scheme is regulated by a contract that clearly defines the obligations of the parties whose main element is the obligation of the physician to meet the provision of health services for insured persons under the procedures established by the insurance scheme. This service is paid by the insurance scheme under the terms of the contract.

After legislative changes and especially with the entry into force of the Decision no. 857, dated 20/12/2006 "On the financing of primary health care services from the compulsory health care insurance scheme" all primary health care is funded by $\mathrm{HII}$ and partly funded by the $\mathrm{MoH}$ in terms of investments. Funding from the scheme is performed through contracts, which are already bided not simply between HII and doctors but between HII and health centers. HC-s provide primary health care as a public non- budgetary and non- profitable juridical person. Health centers are responsible for the use of funding from HII. According to this decision, HII gains independence in providing its services to insured persons, being the direct contractor of $\mathrm{HC}$-sand monitored of their performance.Meantime, the minimum package of services that HS-s will provide is determined by the Ministry of Health and approved by the Council of Ministers. Additional services and those offered to uninsured individuals are determined by special agreements between the $\mathrm{MOH}$ and $\mathrm{HII}$.

Such a method of financing and controlling of health care centers by HII is considered as too much advanced, as it enables the further development of service delivery conditions and hiring of qualified medical personnel. A significant element is the principle of non-discrimination in the delivery of services to the population, the confidentiality of data and the demand for the establishment of quality standards. It should be noted that the establishment of this form of financing has led to maintaining the transparent procedure of the population access to health services at the same levels. The main requirement of the procedure is the submission of the health booklet, which proves if the patient's is insured or not. 


\subsubsection{Coverage of the costs of hospital health services}

An expansion of health benefits for insured persons through hospital services is regulated in detail with DCM. 1661 dated 29.12.2008 "For the financing of hospital health services from the compulsory health care insurance scheme". The scheme is currently extended only in public hospitals(World Health Organization Statistical Information System)and procedural requirements for the insured are two: provision of proofs of the insured status through health booklet and implementation of the referral system, which means addressing to the hospital with a recommendation from the primary health system. Persons that do not comply with these procedures, receive the hospital services after paying the relevant fees.

It is intended that the procedures of benefiting hospital health service on the part of the insured become as simple as possible, by shifting the weight of formalities and documents on the hospital or service provider. The decision provides for the drafting of a contract between the hospital and health insurance institute in which the parties define the respective obligations regarding delivery of services to the insured persons and the payment for rendered services.

\subsubsection{Coverage of unique tertiary examinations}

Coverage of unique tertiary examinations, otherwise known as coverage of expensive equipment, which are located in university level hospitals, is regulated in detail with DCM. No. 383, dated 19/06/2004 "On the approval of procedures, fees and the extent of coverage of unique and tertiary service included in health insurance."We mean here the screening services such as scanner, magneticresonance, coronarographia etc. This Act sets out the conditions and procedures for benefiting. This service will be provided to those insured persons owning the health booklets and observing the recommendation system starting from the family doctor, specialist etc. The Council of Ministers has defined groups of insured persons who receive this health service free of charge and those who receive it through co-payment. Thus, children up to 12 years old, totally disabled and war veterans as well as TB and CA patients profit the health service coverage cost at a rate of 100 percent, while other economically active categories are covered at a rate of $90 \%$ and $10 \%$ are covered by co-payments. Uninsured or persons or those who have not respected referral system pay the full cost.

\subsubsection{Coverage of a part of drug prices}

The scheme covers drugs contained in the "List of reimbursed drugs". This list is approved on annual basis and the list approved by DCM, no 471 date 18.07.2012" For the adoption of the reimbursed drugs list by HII and the extent of their coverage" is actually in force.

The list contains 402 reimbursed medicines as well as their alternatives. If for a drug exist so many other alternatives, the scheme will cover the price of the less expensive drug.

The principle of participation or co-payment is implemented in the drugs coverage. According to this principle, health insurance scheme covers a part of the drug price and the rest is paid by the insured persons at the pharmacy(Law no. 7870, 1994). The insured individuals profit drugs in the pharmacy through full or partial refunded prescriptions, or no refunded prescriptions. Ministry of Health and HII set rules both for the manner of fulfillment and execution of prescription from pharmacies that have a contract with HII. While reimbursable prescription format is defined by HII itself.

Prescriptions with full refund are issued to certain protected categories just like veterans, children 0-12 months, pensioners, people suffering from some serious diseases such as cancer, tuberculosis, blood diseases etc.. The copayment for these prescriptions is zero, which means that the insured pay nothing. For other categories, partially refunded prescriptions are issued for the most part of drugs, which meansthat these drugs are received through copayment. Uninsured persons pay the full price of the drug. Only individuals supplied with health booklet are benefiting through receiving reimbursed drugs.

\section{Overview of European Health Insurance Scheme}

\subsection{European social objectives in the context of the European Code of Social Security}

Social rights have played a very important role in European development during the last century, but despite progress in many areas, not all Europeans enjoy them. Council of Europe began work on projects in 1999 to find solutions to the many problems faced by individual citizens when they try to seek the right to social protection, housing, health and 
education. One of the legal instruments of the Council of Europe is the European Code of Social Protection.

European Code of Social Security and its Protocol guarantee minimum protection, including among other things, medical care, health insurance, compensation for work injuries, maternity, unemployment, invalidity and survivors' benefits, family allowances and pensions. Revised Code (1990) takes into account recent changes in the social security legislation in the member states and improves the protection guaranteed at national level.

European Code of Social Protection represents a minimum standards. It's aim is not the standardization of national social protection systems. Standardization would require all contracting parties to provide the same benefits for the same categories of the population, to the same extent and in the same conditions. Instead, the Code recognizes the will of harmonization of social protection systems and the establishment of minimum requirements that must be met by the states. This scope is guaranteed at least a certain minimum level of social protection. If states can and want to provide more than this minimum conditions, they are free to do that.

Code respects the diversity and individuality of the national defense of social systems le features products, the economical, social, and political tradition among which are developing countries. In this way the code determines what should be achieved and at the same time allows each state to decide how to achieve those goals. The particularity is that the goals are desined in such a way that can be applied to all types of social protection systems, whether it refers to employment protection, certain categories of employees, all economically active population or the entire resident population.

European code for each branch defines the scope of application (contingencies covered, protected persons), the level of benefits; qualifying for benefits; benefit period; period until the beginning of the benefit recipient.

The European Code of Social Security include this type of medical care benefits:(Article 10, of the European Code of Social Security)

- Care by general practitioners (GPs), who are also sometimes called "family doctors" or "primary care providers". Often GPs will act as the first port of call for patients and will be responsible for authorizing specialist or hospital treatment. As well as providing GP care the contracting parties must also provide for home visits by GPs;

- Specialist care in hospitals either on an in-patient or an out-patient basis. Any specialist care that can be reasonably provided outside the hospital infrastructure should also be made available;

- Essential drugs but only if they are prescribed by doctors or specialists;

- medical rehabilitation, including the supply, maintenance and renewal of prosthetic and orthopedics appliances prescribed by doctors or specialists;

The personal scope of health care can be organized in a number of ways. An important distinction to make is that between the provision of derived rights and individual rights. Systems that operate through derived rights will usually base entitlement on employment or economic activity, this means that employees or the economically active are directly entitled to medical care. These rights are then extended to the wives and children of the employee or economically active person, in other words the wives and children derive their entitlement to medical care from the employees or economically active people in their family. Systems that base entitlement on residence provide individual rights so that every man, woman and child is directly entitled; their rights are not derived from anyone else. The Code makes provision for systems that are based upon derived rights stemming from employment or professional activity as well as those systems offering individual rights based upon residence.

\subsection{The compulsory health care insurance scheme of Slovenia}

The compulsory health insurance covers all population with permanent residence in Slovenia, which is covered under the unique compulsory insurance scheme either as mandatory member or as their (family) dependents. Virtually the entire (100\%) population is insured. Coverage of the individual under compulsory health insurance is, in principle, related to his contribution, which entitles insured individuals and their family members to services. There are 21 categories of insured persons,(OECD Health , 2011)which can be grouped into some main types. the largest category comprises all employed workers whose contributions are dependent on income or on other bases for payment of contributions (farmers pay a proportion of their cadastral income or of the basis for pension and disability insurance respectively; natural persons, independently performing business or professional activity as their only or prime occupation pay a proportion of the gross basis for pension and disability insurance, etc. Pensioners also pay certain proportion of their gross pensions. the second group comprises categories whose contributions are fixed amounts. socially disadvantaged groups are covered under different mechanisms from state or local self-government budgets. the employment service of Slovenia 
pays a fixed contribution for each unemployed person who receives financial benefits from the mentioned service. Social groups with no income are registered in local communities which pay a fixed contribution, family members are insured if they have permanent residence in the republic of Slovenia (unless it is defined otherwise by international agreement), a child is health insured as a family member up to the age 15 years, or up to the age of 18 years if (s)he is not insured in other way, and after this age if he is attending school, i.e., to the end of regular education. From legal point of view, no one can not be insured. But there is always a small group of people without settled insured status and in this context the compulsory health care insurance scheme of Slovenia offered the voluntary health insurance scheme.

\subsubsection{Rights to health care services}

The most comprehensive range of rights present the rights to health care services derived from the compulsory health insurance to which all insured persons are entitled to. These are preventive examinations and services (general health check-ups, measures for prevention of infectious diseases, measures for early detection of certain diseases, etc.), services for prevention, detection and treatment of illnesses on all levels of health sector, treatment and nursing care at home and in special social institutions and in nursing homes for senior citizens, emergency transportation by vehicles, drugs listed in the special list and medical and technical aids (orthopedic, orthotic, eye, ear and other aids).(OECD,Health policies, list of latest publications)

The implementation of certain rights (health resort treatment, temporary absence from work exceeding 30 days, certain most expensive medical devices) is subject to a prior opinion and approval by HII expert medical doctors and HII expert bodies. If an insured person considers his/her health insurance rights to have been violated, he/she may request the arbitration of the disputed matter in HII expert bodies which operate as senates of three members. as a last resort, the insured person may request judicial protection. As concerning the rights to health care services, medical drugs and aids, there exist no differentiation among insured persons. everybody has unrestricted rights to seek help from his/her personal doctor, or, in cases of emergency, from any other medical doctors as well. But compulsory health insurance does not always cover all health care services and not in full prices. Namely health care legislators alleviated constant discrepancies between the economic potential of funds and real costs of health care programmers by introducing specific cost-sharing and co-payments mechanisms. The act has defined certain groups and diseases which are granted to be covered in full price (100\%) by compulsory insurance.

These services for specific groups and diseases described above are covered to $100 \%$ by compulsory health insurance other services are covered only in a certain share of the total value of the service. Percentages have been introduced by the act allowing, HII to decide upon exact level of co-payments but within the legal framework. for example the level of co-payments vary from a minimum of $15 \%$ to a maximum of $95 \%$, and thus determine the minimum or maximum level of co-payments to be paid by the patients. Thus compulsory health insurance covers, in the case of health care services (including drugs, medical and technical aids), the full prices only for legally described groups and certain diseases. In the cases of all other services and population groups, the compulsory health insurance covers just certain percentages of their full prices. The difference to the full price shall either be covered by the insured person himself, or can be covered by the voluntary health insurance company, at which the person has taken a voluntary health insurance policy for copayments. Since 1993 (World Health Organization Statistical Information System, Core Health Indicators) such regulation of compulsory health insurance which presume co-payments and cost-sharing in the system has opened good opportunities to a wide affirmation of the voluntary complementary health insurance.

\subsubsection{Financing of compulsory health insurance}

The contributions for the compulsory health insurance are the main source of financing the compulsory health insurance. The contributions are collected from different categories of insured persons, who contribute the largest share of the income, pay the contribution as a certain percentage of their gross salaries, while their employers also pay a similar amount. In Slovenia, the aggregate contribution rate for active insured persons was corrected only once in the past 10 years, namely in 2002 when it rose from $13.25 \%$ to the present $13.45 \%$ of gross salary. The above is broken down into the employee's contribution totaling to $6.36 \%$ while the employer's totals to $6.56 \%$; employers, however contribute the further $0.53 \%$ for occupational diseases and injuries at work. (World Health Organization ,Regional Overview of Social Health Insurance Europe)The retired persons only pay the contribution, equal to the employee's share. The basis for determining the contribution in case of farmers is their cadastral income or the basis for pension and disability insurance. For other categories of contributors, a flat-rate contribution is determined ranging approximately around the contribution 
rate of an employee with a minimum salary. In addition to that, the employers and those organizing different public works are obliged to pay a special contribution for covering occupational diseases and injuries at work.

\section{Conclusions and Recommendations}

In all examined health insurance scheme we see that systems are based on the structure of self-governance which consist of patients, health care providers both ambulatory and hospital and such third party payer insurance. Within the legal framework set by the government, these layers operate largely autonomously, providing health care as well as generating and distributing health resources.

From this overview of the compulsory insurance scheme health care, we conclude that the right to health insurance as a social-economic right, guaranteed not only by the constitutional provisions but also by specific legislation which establishes specific procedures how this right, the body responsible for its security and regulates relations arising between persons benefiting from this right, health care providers and the administration responsible for health insurance.

Health insurance is a compulsory and universally insurance scheme and as covering all RA citizens with permanent residence in Albanian. Participation in the scheme is based on the payment of contributions. All persons participating in the scheme are considered insures. Health insurance contributions are personal, so it cover only the person who pays or which pays thecontribution and not cover their member of families.

The particularity of this scheme is that if there is delay in the payment of contributions of more than 1 month, the person is not entitled to benefit from the scheme for the period that is covered by contributions.

Health insurance scheme does not have qualification or waiting periods. In this sense, the benefits of the scheme can be obtained the day after, the day that the person has paid contributions for the first time. Also, benefits from this scheme are given equally to all insured persons who have the same health needs, regardless of the the contribution that has made each of them.

The principle of participation or co-payment. According to this principle the health insurance scheme covers a fraction of the price of the drug and the rest been payed by the insured people at the pharmacy.

Internal legislation creates the possibility that potentially all Albanian citizens, but also foreigners who live in Albania to be insured.

Starting from a general point of view and experiences of the above health insurance schemes and based on the requirements of the European Code of Social Security, would recommend the following.

- To review the possibility of increasing the amount of compulsory health insurance contribution, taking into account all the country's economic and social factors.

- To assess the possibility of extending the services offered in the basic package of mandatory health insurance.

- Review beneficiary categories regarding the inactive which, as the third age category (or old age which is an integral categories European Code of Social Security).

- $\quad$ The inclusion of the family benefits to the compulsory health insurance scheme.

\section{References}

DCM no. 383 "Approbation of procedures, fees and cover rate for uncial and tertiary examination that are included in the health insurance",2004

DCM no.87 "Administration and covering of the expenses for the reimbursement prescription" (amended),2006

DCM no. 87 "Identification and obligations of the individuals that benefit from the health services in the Republic of Albania" (2003)

Dr. Paul Schoukens, European Union competencies in the field of social security, EU publication.

DCM no. 857, "On the financing of primary health care services from the scheme compulsory health insurance" (2006).

DCM no. 1661, "On the financing of hospital care scheme mandatory health care Insurance" (2008)

DCM no. 86, " The health Booklet" (2003)

European Code of Social Security, Strasbourg, (1996).

Elizabeth Doctor and Howard Oxley. "Health-Care Systems: Lessons from the Reform Experience". OECD (2007). Health policies, a list of latest publications by OECD.

Lindenlaub Yvonne, Manthei Galina and Schulte Ortwin, EU - Health insurance systems in comparison- Differences and Common Denominators -A Study for the GTZ Consultancy Project on Health sector reform in Albania, Berlin, (2008).

Law no.8417 dt 28.10.1998 Constitution of the Republic of Albania.

Law no.7870,"Health Insurance in the Republic of Albania "amended(1994)

OECD Health: Statistics and Indicators for 30 Countries, (2008). 
Overview of Health Care Financing". World Health Organization, retrieved August 18, (2009)

Prof. Dr.DennyPieters, Social security system of Albania.

Regional Overview of Social Health Insurance in Europe, World Health Organization

Witter Sophie and Ensor Tim, An introduction to health economics

http://www.euro.who.int/observatoryHealth Systems in Transition (HiT) profile for Balkan countries

http://www.euro.who.int/Document/Obs/Eurohealth Health challenges in South Eastern Europe 